\title{
Behaviour, heart rate, and heart rate variability in pigs exposed to novelty
}

\author{
Manja Zupan ${ }^{1,3}$, Tore Framstad ${ }^{1}$, Adroaldo José Zanella ${ }^{2,4}$ \\ 1 NMBU School of Veterinary Science, Department of Production Animal Clinical Science, Animal Welfare Research Group, Oslo, Norway.
2 Norwegian University of Life Sciences, Department of Animal and Aquacultural Sciences, As, Norway.
${ }^{3}$ University of Ljubljana, Biotechnical Faculty, Department of Animal Science, Domžale, Slovenia.
${ }^{4}$ Universidade de São Paulo, Faculdade de Medicina Veterinária e Zootecnia, Departamento de Medicina Veterinária Preventiva e Saúde Animal,
Pirassununga, SP, Brasil.
}

\begin{abstract}
In the present study, we investigated behavioural responses and determined parameters of heart rate variability (HRV) to elucidate a relative activation of autonomic nervous system (ANS) during baseline (10 min) and in response to potentially stressful situations $(10 \mathrm{~min})$ in two pig breeds and sexes. Gilts $(\mathrm{n}=21)$ and barrows $(\mathrm{n}=9)$ of the Landrace $\times$ Yorkshire $(L Y ; n=15)$ and Landrace/Yorkshire $\times$ Landrace/Duroc $(L Y L D ; n=15)$ breeds were subjected to a novel object test (NOT) and a novel arena test (NAT). Basal ANS state differed in pigs across breeds but not sexes. Landrace $\times$ Yorkshire pigs had a significantly lower basal heart rate (HR) and low-frequency band (LF) with a higher root mean square of successive interbeat intervals (RMSSD) and high-frequency band (HF) than LYLD pigs. In the NOT, despite having similar cardiac responses, gilts had a longer duration of contact with a novel object, higher lying and standing duration, and a lower duration of walking compared with barrows. In the NAT, we found similar behaviour across sexes but a different degree of ANS state, with barrows having a significantly higher increase in LF/HF (power of the low frequency component divided by the power of the high-frequency band) compared with gilts. Landrace/Yorkshire $\times$ Landrace/Duroc pigs showed longer duration of contact with a novel object in the NOT accompanied by less lying and standing than LY pigs in both tests. No difference in ANS activation between breeds was found in the NOT. In the NAT, HR increased more from baseline to testing in LY pigs than in LYLD pigs. There is a complex and often contradictory nature of relationships between behaviour and cardiac responses to novelty in pigs of different breeds and sexes.
\end{abstract}

Key Words: breed, Sus scrofa

\section{Introduction}

Heart rate variability (HRV) is a valid, non-invasive method to assess autonomic nervous system (ANS) regulation of cardiac activity in relation to stress responses and welfare (von Borell et al., 2007). It reflects an ever changing psycho-physiological state of the animal that is regulated by the parasympathetic (vagal) and sympathetic branches of the ANS (Mohr et al., 2002).

The basal autonomic state, i.e., during non-challenging conditions, can be considered an index of the susceptibility of an individual to stress, since individuals exposed to stressful situations show lower vagal tone, potentially being more vulnerable to stress (Porges, 1995). Recently, HRV was used as a method to assess the impact of the ANS on

Received August 20, 2015 and accepted December 18, 2015.

Corresponding author: manja.zupan@bf.uni-lj.si

http://dx.doi.org/10.1590/S1806-92902016000300006

Copyright (c) 2016 Sociedade Brasileira de Zootecnia. This is an Open Access article distributed under the terms of the Creative Commons Attribution License (http://creativecommons.org/licenses/by/4.0/), which permits unrestricted use, distribution, and reproduction in any medium, provided the original work is properly cited. cardiac activity in pigs in relation to tail biting (Zupan et al., 2012). It was found that both victims of tail biting and biters might have a dysfunctional autonomic regulation.

In an intensive as well as in an outdoor pig production unit, several animal welfare problems such as tail-biting and belly nosing have been recognised (Hansson et al., 2000; Walker and Bilkei, 2006), which points out that at least some animals cannot cope with the environment. To the awareness of the authors, there is a lack of data concerning the measurement of the relationship between behavioural and physiological characteristics under fearinduced situations in pigs. The aim of our study was to investigate changes in HRV for the better understanding of sex and breed effects on pig behaviour and cardiac activity in novel situations.

We focused on sources of variation in behavioural and cardiac responses by means of heart rate (HR) and of HRV related to sex and breed in the two fear tests: a novel object (NOT) and a novel arena test (NAT). The same animals have been analysed before in relation to tail biting (Zupan et al., 2012). We tested gilts and barrows of two crossbreeds. In our previous paper (Zupan et al., 2012), it was demonstrated that tail biters, victims of tail biting, and control pigs respond 
differently to a novel positive or negative environment due to having different emotional processing and autonomic regulation of HRV. To fully assess the validity of HRV measures to identify susceptible phenotypes, knowledge of the relationship between behavioural and physiological characteristics and specific external factors, such as responses of the ANS to different stressful challenges, should be further investigated to better understand what consequences tail biting has on pigs. It has been documented that pigs have a great individual different behaviour as well as physiology (Jensen et al., 1995; Geverink et al., 2002; Taylor et al., 2010). In our study, we hypothesise to find an individual variation in pigs of different breeds and sexes, with pigs showing generally more fear in a NAT than in a NOT. This is based on a literature survey showing that social isolation in a novel environment is one of the most stressful situations for all social species including pigs, leading animals to suffer from separation anxiety (Forkman et al., 2007).

\section{Material and Methods}

Data were collected from animals that were previously analysed with respect to tail biting behaviour and measures of HR and HRV (Zupan et al., 2012). Briefly, 30 pigs (above 110 days old) with intact tails were selected based on the frequency of biting during a 60-min observation period on a farm. The pens were of mixed sex. Pigs were housed at 12 pigs per pen. Pigs were of two crossbreeds: Landrace $\times$ Yorkshire (LY) and Landrace/Yorkshire $\times$ Landrace/Duroc (LYLD). A particular phenotype consisted of three barrows (LY: $\mathrm{n}=2$; LYLD: $\mathrm{n}=1$ ) and seven gilts (LY: $\mathrm{n}=3$; LYLD: $n=4)$. After selection on a farm, the pigs were transported to the research facilities where they were weighed and housed individually in pens in the same room. Pelleted concentrate and water were available ad libitum via a trough and water nipple, respectively. The body weight of the tested pigs ranged from $28 \mathrm{~kg}$ to $70 \mathrm{~kg}$.

The experimental setting was as described in Zupan et al. (2012). Pigs were tested in five blocks of six pigs per block, with two trios per block. Briefly, behavioural and physiological responses by the measures of HR and HRV were recorded during the NOT and the NAT. Animals were exposed to the tests one time each. After the habituation period, the NOT was carried out in the home pen of a pig $(1.25 \times 1.79 \mathrm{~m})$. The Polar device, which consisted of a wristwatch computer and a HR belt, to measure HRV, was fitted on the pigs and basal recording followed for duration of $10 \mathrm{~min}$. Afterwards, the test person entered the pen and switched off the wristwatch computer and tied a string with a novel object, i.e., the white container with black painted stripes of a bucket size, to the middle of the pen. The person turned on the Polar device and exited the pen. The continuous 10 min of test period followed.

The NAT was conducted on the following day. Basal HR data were collected as described for the NOT. The pig was then gently herded by the test person from the pen down a short corridor to the test room $(1.95 \mathrm{~m} \times 2.80 \mathrm{~m})$ where it was exposed to social isolation. There, the behavioural and cardiac responses of an individual pig were recorded continuously for $10 \mathrm{~min}$. After each test session in a novel room, the pig was returned to its pen and the room was thoroughly cleaned with water and a brush.

Behaviours scored (Table 1) are similar to the definitions of Zupan et al. (2012). The behaviour of the pigs was recorded using the MSH digital video system program (MSH-video, Riga, Latvia, http://www.guard.lv/eng/index.php) and continuously scored using a PC and the Observer software package XT 7.0 (Noldus Information Technology 1997). The behavioural scoring of an individual pig started after the test person exited the pen or novel room and lasted for the following $8 \mathrm{~min}$.

The HR monitor system (RS800TM155, Polar Electro Oy, Helsinki, Finland) set up at $1000 \mathrm{~Hz}$ sampling rate consisted of a flexible belt with two integrated electrodes, a transmitter, a separate storage device, and corresponding software (Polar Precision Performance Software, version 5). The HR monitor system was designed to store time series of interbeat intervals (IBI) of consecutive heartbeats and validated for pigs (Marchant-Forde et al., 2004). Spurious measures in the IBI were corrected using a correction function within the Polar software with the standard setup. In the software, pre-defined standard settings in the scissor check box were: filter power $=$ moderate, protection zone $=6$, and activation of the check box for elimination

Table 1 - Definitions of behaviours observed in the novel object test (NOT) and novel arena test (NAT)

\begin{tabular}{ll}
\hline Behaviour & \\
\hline Lying (duration) & Lying or sitting without investigation of novel object \\
Standing (duration) & Standing without investigation of novel object \\
Walking (duration) & Locomotion of more than one step without investigation of novel object \\
Object investigation (duration, latency) ${ }^{1}$ & Nosing, biting, licking, or manipulating novel object \\
\hline${ }^{1}$ NOT only. &
\end{tabular}


of supraventricular beats. Data with a corrected error rate above $5 \%$ were excluded from the analysis. Recordings with longer sequences of equal values in the tachogram were discarded as well. Then, we selected the first continuous 5 -min time window of acceptable quality. A time segment of $10 \mathrm{~min}(5 \mathrm{~min}$ before test period; i.e., basal and $5 \mathrm{~min}$ during test period) was selected for analysis.

We analysed HR (beats per min, bpm) and HRV in the time domain (the root mean square of successive differences in IBI, RMSSD, ms) and the frequency domain (power of the low-frequency band, LF; power of the high frequency band, HF; and LF/HF ratio; see von Borell et al., 2007). The frequency limits that correspond to von Borell et al. (2007) were set at 0.03 to $0.10 \mathrm{~Hz}$ for the LF band and 0.13 to 0.41 $\mathrm{Hz}$ for the HF band.

The statistical analysis was performed on SAS (Statistical Analysis System, version 9.1) using total number of recordings (Table 2). Results are shown as means \pm standard error (SE), and all reported P-values are 2-tailed. The data residuals were tested for normality (UNIVARIATE procedure) and when a normal distribution of the residuals could not be assumed, data were either $\log$ transformed (Tables 5, 6, and 7) or an analysis was performed using non parametric statistics (behavioural data). Significance was indicated by $\mathrm{P}<0.05$ and a tendency by $\mathrm{P}<0.10$. The fixed effects investigated were phenotype, breed, and sex. The present study focuses on breed and sex effects, and effects of phenotype are reported in a previous paper (Zupan et al., 2012).

The GENMOD procedure that fits generalized linear models was utilized for records of behaviour in the tests. The dependent variables were count values per animal (excretion frequency) or the duration of time in seconds (other recorded variables).

The GLM procedure was applied for each of the cardiac parameters separately. Pair-wise differences were tested by a multiple post hoc Tukey-Kramer test. Individuals were used as the subject for the repeated statement. The effect of body weight was tested in each model as a covariate but no significant effect was found.

Baseline data were used as covariate in the models. While in the NAT a significant influence of breed on HR was found, walking duration data were added as a covariate in the model to assess the effect of physical activity on HR. Activity could not explain variance in the data.

To investigate Spearman correlation coefficients, procedure CORR was used to assess the relationship between the HRV variables in all tested conditions. In the text, only Bonferroni-corrected statistical significant values are reported $(\mathrm{P}<0.05, \mathrm{~B}: \mathrm{P}<0.004)$.

Table 2 - Total number of pigs used for particular statistical analysis

\begin{tabular}{|c|c|c|c|c|c|}
\hline & Test & Fixed effect & $\mathrm{N}$ & Level & $\mathrm{n}$ \\
\hline \multirow[t]{5}{*}{ Behaviour } & Novel object test & Sex & 24 & Gilt & 15 \\
\hline & & & & Barrow & 9 \\
\hline & & Breed & & LY & 14 \\
\hline & Novel arena test & Sex & 27 & Gilt & 17 \\
\hline & & & & LYLD & 13 \\
\hline \multirow{4}{*}{$\begin{array}{l}\text { Heart rate variability } \\
\text { (baseline) }\end{array}$} & & Sex & 13 & Gilt & 9 \\
\hline & & & & Barrow & 4 \\
\hline & & Breed & & LY & 9 \\
\hline & & & & LYLD & 4 \\
\hline & & Breed & & LY & 9 \\
\hline & & & & LYLD & 5 \\
\hline & Novel arena test & Sex & 11 & Gilt & 8 \\
\hline & & & & Barrow & 3 \\
\hline & & Breed & & LY & 7 \\
\hline & & & & LYLD & 4 \\
\hline
\end{tabular}

$\mathrm{N}$ - total number of pigs used; $\mathrm{n}$ - total number of pigs used for a particular level; LY - Landrace $\times$ Yorkshire; LYLD - Landrace/Yorkshire $\times$ Landrace/Duroc. 


\section{Results}

In the NOT, it was observed that three animals did not make contact with the novel object. Gilts demonstrated longer duration of lying and standing plus longer duration of contact with a novel object but shorter duration of walking compared with barrows $(\mathrm{P}<0.05)$. The behavioural responses in the NAT test did not differ between sexes. Analyzing the breed differences during the exposure to the NOT, the duration of lying, standing, and walking was longer in LY pigs, while the duration of contact with a novel object was longer in LYLD pigs $(\mathrm{P}<0.05)$ (Table 3). A different picture emerged in the NAT, in which a longer duration of standing but shorter duration of walking was shown in LY pigs compared with LYLD pigs $(\mathrm{P}<0.05)$ (Table 4).

The combined baseline values of the cardiac activity parameters differed between breeds but not between gilts and barrows (Table 5). In detail, LY pigs had a significantly lower baseline HR and LF with a higher RMSSD and HF than LYLD pigs $(\mathrm{P}<0.05)$. When looking at the correlations between parameters of HRV, patterns

Table 3 - Effect of sex and genotype on behaviour during the novel object test

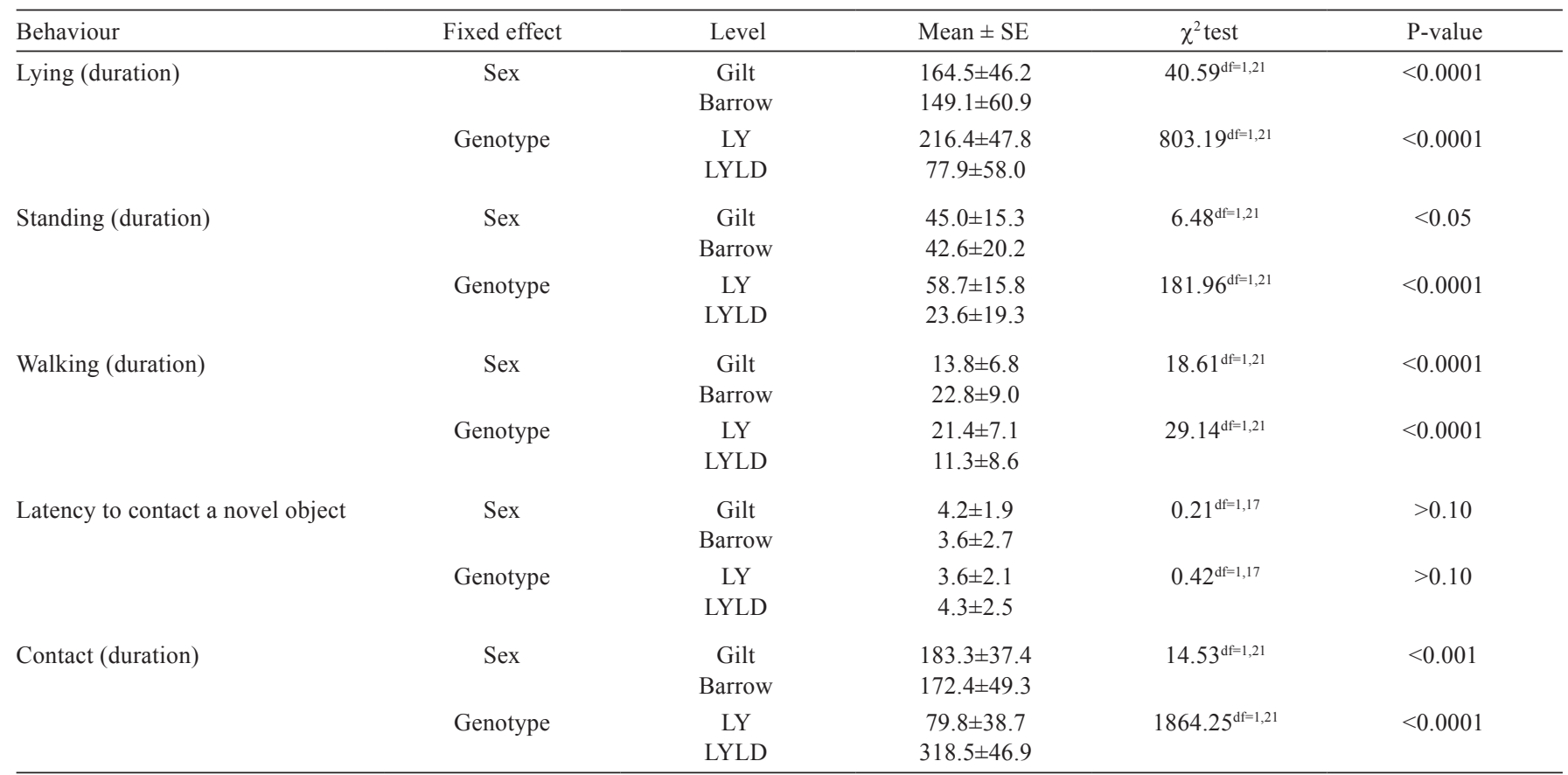

SE - standard error.

LY - Landrace $\times$ Yorkshire; LYLD - Landrace/Yorkshire $\times$ Landrace/Duroc.

The data were modeled for a particular behavioural variable using phenotype, breed, and sex as tested effects. Results are presented in seconds and standard errors.

Table 4 - Effect of sex and genotype on behaviour during the novel arena test

\begin{tabular}{|c|c|c|c|c|c|}
\hline Behaviour & Fixed effect & Level & Mean $\pm \mathrm{SE}$ & $\chi^{2}$ test & P-value \\
\hline \multirow{4}{*}{ Lying (duration) } & Sex & Gilt & $56.1 \pm 22.2$ & $0.12^{\mathrm{df}=1,24}$ & $>0.10$ \\
\hline & & Barrow & $54.4 \pm 29.6$ & & \\
\hline & Genotype & LY & $\begin{array}{l}55.9 \pm 24.4 \\
551+261\end{array}$ & $0.38^{\mathrm{d} f=1,24}$ & $>0.10$ \\
\hline & & & $55.1 \pm 26.1$ & & \\
\hline \multirow[t]{2}{*}{ Standing (duration) } & Sex & Gilt & $254.8 \pm 18.3$ & $0.16^{\mathrm{df}=1,24}$ & $>0.10$ \\
\hline & & Barrow & $255.3 \pm 24.3$ & & \\
\hline \multirow[t]{4}{*}{ Walking (duration) } & Sex & Gilt & $169.1 \pm 9.9$ & $0.72^{\mathrm{df}=1,24}$ & $>0.10$ \\
\hline & & Barrow & $170.3 \pm 13.3$ & & \\
\hline & Genotype & LY & $157.9 \pm 10.9$ & $23.68^{\mathrm{df}=1,24}$ & $<0.0001$ \\
\hline & & LYLD & $182.0 \pm 11.7$ & & \\
\hline
\end{tabular}

SE - standard error.

LY - Landrace $\times$ Yorkshire; LYLD - Landrace/Yorkshire $\times$ Landrace/Duroc.

The data were modeled for particular behavioural variable using phenotype, breed, and sex as tested effects. Results are presented in seconds and standard errors. 
Table 5 - Effect of sex and genotype on mean heart rate (HR) and heart rate variability parameters during baseline measurements

\begin{tabular}{|c|c|c|c|c|c|}
\hline Parameter & Fixed effect & Level & Mean $\pm \mathrm{SE}$ & F-value & P-value \\
\hline \multirow[t]{2}{*}{ HR (bpm) } & Sex & $\begin{array}{c}\text { Gilt } \\
\text { Barrow }\end{array}$ & $\begin{array}{l}153.6 \pm 5.3 \\
156.6 \pm 5.9\end{array}$ & $0.15^{\mathrm{df}=1,11}$ & $>0.10$ \\
\hline & Genotype & $\begin{array}{c}\text { LY } \\
\text { LYLD }\end{array}$ & $\begin{array}{l}149.5 \pm 3.8 \\
165.6 \pm 5.7\end{array}$ & $5.50^{\mathrm{df}=1,11}$ & $<0.05$ \\
\hline RMSSD (ms) & Sex & $\begin{array}{c}\text { Gilt } \\
\text { Barrow }\end{array}$ & $\begin{array}{l}22.7 \pm 4.5 \\
18.6 \pm 5.1\end{array}$ & $0.40^{\mathrm{df}=1,11}$ & $>0.10$ \\
\hline \multirow[t]{2}{*}{$\log 10 \mathrm{LF}$} & Sex & $\begin{array}{c}\text { Gilt } \\
\text { Barrow }\end{array}$ & $\begin{array}{c}1181.2 \pm 214.8 \\
630.2 \pm 322.2\end{array}$ & $0.04^{\mathrm{d} f=1,11}$ & $>0.10$ \\
\hline & Genotype & $\begin{array}{l}\text { LY } \\
\text { LYLD }\end{array}$ & $\begin{array}{c}1292.6 \pm 198.4 \\
379.5 \pm 297.5\end{array}$ & $6.84^{\mathrm{df}=1,11}$ & $<0.05$ \\
\hline $\log 10 \mathrm{HF}$ & Sex & $\begin{array}{c}\text { Gilt } \\
\text { Barrow }\end{array}$ & $\begin{array}{c}136.7 \pm 39.0 \\
73.5 \pm 43.9\end{array}$ & $0.45^{\mathrm{df}=1,11}$ & $>0.10$ \\
\hline \multirow[t]{2}{*}{$\mathrm{LF} / \mathrm{HF}^{1}$} & Sex & $\begin{array}{c}\text { Gilt } \\
\text { Barrow }\end{array}$ & $\begin{array}{l}1070.5 \pm 140.9 \\
1146.4 \pm 158.4\end{array}$ & $0.01^{\mathrm{df}=2,10}$ & $>0.10$ \\
\hline & Genotype & $\begin{array}{c}\text { LY } \\
\text { LYLD }\end{array}$ & $\begin{array}{c}1150.9 \pm 119.3 \\
965.4 \pm 177.9\end{array}$ & $0.12^{\mathrm{df}=2,10}$ & $>0.10$ \\
\hline
\end{tabular}

SE - standard error.

LY - Landrace $\times$ Yorkshire; LYLD - Landrace/Yorkshire $\times$ Landrace/Duroc.

RMSSD - root mean square of successive R-R intervals; log $10 \mathrm{LF}$ - log transformed values tested for power of the low-frequency band; log $10 \mathrm{HF}$ - log transformed values tested for power of the high-frequency band; LF - power of the low-frequency band; HF - power of the high-frequency band.

${ }^{1}$ Calculated on the original values of LF and HF.

Table 6 - Mean heart rate (HR) and heart rate variability parameters of pigs of different sexes and genotypes while pre-tested (baseline) and tested in the novel object test

\begin{tabular}{|c|c|c|c|c|c|c|}
\hline \multirow{2}{*}{ Parameter } & \multirow{2}{*}{ Fixed effect } & \multirow{2}{*}{ Level } & \multicolumn{2}{|c|}{ Mean $\pm \mathrm{SE}$} & \multirow{2}{*}{ F-test } & \multirow{2}{*}{ P-value } \\
\hline & & & Baseline & Testing & & \\
\hline \multirow[t]{4}{*}{$\log 10 \mathrm{HR}$ (bpm) } & Sex & Gilt & $152.6 \pm 7.9$ & $142.5 \pm 7.7$ & $0.03^{\mathrm{df}=5,8}$ & $>0.10$ \\
\hline & & Barrow & $152.7 \pm 8.9$ & $160.5 \pm 8.6$ & & \\
\hline & Genotype & LY & $146.8 \pm 6.9$ & $143.6 \pm 6.8$ & $1.03^{\mathrm{df}=5,8}$ & $>0.10$ \\
\hline & & LYLD & $163.2 \pm 9.6$ & $162.2 \pm 9.3$ & & \\
\hline \multirow[t]{2}{*}{ RMSSD (ms) } & Sex & Gilt & $13.6 \pm 2.7$ & $13.3 \pm 2.4$ & $0.07^{\mathrm{df}=5,8}$ & $>0.10$ \\
\hline & & LYLD & $8.2 \pm 3.3$ & $9.6 \pm 2.9$ & & \\
\hline \multirow[t]{4}{*}{ LF } & Sex & Gilt & $860.9 \pm 249.3$ & $1238.1 \pm 444.6$ & $0.01^{\mathrm{df}=5,8}$ & $>0.10$ \\
\hline & & Barrow & $620.7 \pm 287.9$ & $585.5 \pm 516.6$ & & \\
\hline & Genotype & LY & $160.7 \pm 56.1$ & $1331.1 \pm 412.9$ & $0.02^{\mathrm{df}=5,8}$ & $>0.10$ \\
\hline & & LYLD & $31.1 \pm 75.3$ & $217.7 \pm 555.7$ & & \\
\hline $\mathrm{HF}$ & & LYLD & $13.1 \pm 82.2$ & $41.1 \pm 66.9$ & & \\
\hline \multirow[t]{4}{*}{$\mathrm{LF} / \mathrm{HF}^{1}$} & Sex & Gilt & $1078.8 \pm 181.8$ & $625.8 \pm 109.2$ & $0.12^{\mathrm{df}=5,8}$ & $>0.10$ \\
\hline & & Barrow & $1143.3 \pm 204.4$ & $1022.4 \pm 123.3$ & & \\
\hline & Genotype & LY & $1096.7 \pm 160.4$ & $750.6 \pm 96.8$ & $0.09^{\mathrm{d} f=5,8}$ & $>0.10$ \\
\hline & & LYLD & $1123.9 \pm 221.5$ & $877.1 \pm 133.6$ & & \\
\hline
\end{tabular}

SE - standard error.

LY - Landrace $\times$ Yorkshire; LYLD - Landrace/Yorkshire $\times$ Landrace/Duroc.

$\log 10 \mathrm{HR}$ - log transformed values tested for heart rate; RMSSD - root mean square of successive R-R intervals; LF - power of the low-frequency band; HF - power of the high-frequency band.

${ }^{1}$ Calculated on the original values of LF and HF. 
Table 7 - Mean heart rate (HR) and heart rate variability parameters of pigs of different sexes and genotypes while pre-tested (baseline) and tested in the novel arena test

\begin{tabular}{|c|c|c|c|c|c|c|}
\hline \multirow{2}{*}{ Parameter } & \multirow{2}{*}{ Fixed effect } & \multirow{2}{*}{ Level } & \multicolumn{2}{|c|}{ Mean \pm SE } & \multirow{2}{*}{ F-test } & \multirow{2}{*}{ P-value } \\
\hline & & & Baseline & Testing & & \\
\hline \multirow[t]{3}{*}{ HR (bpm) } & Sex & Gilt & $150.6 \pm 8.8$ & $159.5 \pm 6.5$ & $1.94^{\mathrm{df}=5,5}$ & $>0.10$ \\
\hline & & Barrow & $151.7 \pm 13.2$ & $155.7 \pm 9.7$ & & \\
\hline & & LYLD & $152.8 \pm 13.5$ & $169.0 \pm 9.9 \mathrm{~b}$ & & \\
\hline \multirow[t]{2}{*}{ RMSSD (ms) } & Sex & Gilt & $13.9 \pm 2.1$ & $13.7 \pm 2.0$ & $0.02^{\mathrm{df}=5,5}$ & $>0.10$ \\
\hline & & LYLD & $12.3 \pm 3.3$ & $11.9 \pm 3.1$ & & \\
\hline \multirow[t]{4}{*}{$\log 10 \mathrm{LF}$} & Sex & Gilt & $1151.2 \pm 346.8$ & $1515.0 \pm 607.7$ & $0.02^{\mathrm{df}=5,5}$ & $>0.10$ \\
\hline & & Barrow & $450.6 \pm 561.9$ & $1228.4 \pm 984.5$ & & \\
\hline & Genotype & LY & $1176.2 \pm 387.8$ & $1706.2 \pm 679.4$ & $0.02^{\mathrm{df}-5,5}$ & $>0.10$ \\
\hline & & LYLD & $582.0 \pm 505.6$ & $965.5 \pm 885.8$ & & \\
\hline \multirow[t]{4}{*}{$\mathrm{LF} / \mathrm{HF}^{1}$} & Sex & Gilt & $890.9 \pm 119.9$ & $960.3 \pm 127.8 \mathrm{a}$ & $10.75^{\mathrm{df}=3,7}$ & $<0.05$ \\
\hline & & Barrow & $857.4 \pm 179.0$ & $1013.5 \pm 190 \mathrm{~b}$ & & \\
\hline & Genotype & LY & $995.6 \pm 125.6$ & $885.9 \pm 133.8$ & $2.04^{\mathrm{df}=3,7}$ & $>0.10$ \\
\hline & & LYLD & $682.4 \pm 183.8$ & $1130.3 \pm 195.7$ & & \\
\hline
\end{tabular}

SE - standard error.

LY - Landrace $\times$ Yorkshire; LYLD - Landrace/Yorkshire $\times$ Landrace/Duroc.

RMSSD - root mean square of successive R-R intervals; log 10LF - log transformed values tested for power of the low-frequency band; log $10 \mathrm{HF}$ - log transformed values tested for power of the high-frequency band; LF - power of the low-frequency band; HF - power of the high-frequency band.

${ }^{1}$ Calculated on the original values of LF and HF.

of Spearman correlation showed that in LY pigs, LF was positively correlated with $\mathrm{HF}$ ( $\mathrm{rs}>0.5$ ) and negatively with HR $(r s<-0.7)$. Heart rate was also negatively correlated with HF ( $r s<-0.7)$, while a positive correlation was found (rs $>0.6$ ) between RMSSD and HF. In LYLD pigs, a strong positive correlation was found between RMSSD and LF/HF ratio ( $\mathrm{rs}>0.8$ ). Furthermore, in gilts, HR was strongly negatively correlated with LF and HF (both rs $<-0.8$ ) and LF was positively correlated with HF ( $r s>0.6)$.

The pigs did not develop significant different autonomic responses under NOT (Table 6). Regarding the correlation analysis, it was revealed that in gilts during the test period, LF was strongly positively correlated with both RMSSD and HF, and HF was positively correlated with RMSSD (overall rs $>0.9$ ). In both breeds, HF was found to be strongly positively correlated with RMSSD ( $r s>0.9)$ and LF ( $r s>0.8)$, while in LYLD pigs, an additional positive correlation was found between RMSSD with LF $(r s=+1)$. In the NAT (Table 7), the LF/HF ratio was affected by sex. Barrows showed a significantly higher increase in LF/HF ratio than gilts $\operatorname{did}(\mathrm{P}<0.05)$. During the test period, the ratio was found to be negatively correlated with HF ( $r s=-1)$ in barrows, while RMSSD was positively correlated with LF $(r s=+1)$. In gilts, RMSSD was strongly positively correlated with HF ( $r>0.9)$ and negatively with HR $(r s<-0.8)$. We found a significant difference between breeds in HR during test period. A higher HR was observed in LYLD pigs than in LY pigs $(\mathrm{P}<0.05)$ and the results were not affected by walking activity of the animals (F-value $=$ $0.17 ; \mathrm{df}=5,5 ; \mathrm{P}>0.10$ ). Pigs did not differ in other HRV parameters. With LYLD pigs, the correlation coefficient revealed that during social isolation RMSSD was strongly positively correlated with both LF and HF $(\mathrm{rs}=+1)$.

\section{Discussion}

The most important finding of this study is the difference in basal cardiac activity across breeds but not sexes. Landrace $\times$ Yorkshire (LY) pigs had lower HR with higher RMSSD, LF, and HF when compared with Landrace/ Yorkshire $\times$ Landrace/Duroc (LYLD) pigs. In addition, sex and breed affected behavioural responses during exposure to the NOT, whilst during exposure to the NAT only breed had an effect. Considering the cardiac responses in the NAT, HR increased more from baseline to testing in LY pigs than in LYLD pigs. Sympathovagal dominance also increased more from baseline to test period in barrows (increased $\mathrm{LF} / \mathrm{HF}$ ) than in gilts. 
We observed no difference between gilts and barrows in time or frequency domain parameters during basal, nonchallenging conditions. This could provide evidence of similar allostatic loads (Korte et al., 2007) in the sexes. On the contrary, high baseline levels of vagal tone could be associated with healthy individuals, while low vagal activity may reflect poor allostasis (Korte et al., 2007). By showing higher RMSSD and HF, LY pigs may have had a less suppressed vagal activity than LYLD pigs and may thus be better adapted to different challenges.

During exposure to a novel-challenging situation in the NOT, gilts were witnessed as more exploratory and attentive than barrows, which supports our tested hypothesis. They showed longer duration of time spent actively nosing, biting, licking, or manipulating the novel object and longer duration of standing. It can be argued that showing longer duration of lying, during which animals often spent time manipulating the litter and most likely having their attention directed towards the novel object, is an additional evidence of gilts being more explorative and paying more attention to the novel object that they can manipulate. The behavioural changes observed across sexes together with the lower duration of walking may suggest that gilts may be less fearful than barrows (Forkman et al., 2007). It has been often reported that changes in behaviour follow the changes in physiology, so we would have expected differences in cardiac activity between sexes, but no differences were found. Since a lower motor activity level found in our gilts can be, according to the classical models of motivation (Hughes and Duncan, 1988), seen as a response to a perceived lack of control over the environment, which is stress-induced, we find this less likely when taking into account both behavioural and physiological measurements.

The reverse picture to that seen in the NOT emerged in the NAT, in which gilts showed similar behavioural responses to the social isolation in the novel environment but different cardiac activity compared with barrows. In the NAT, the increased LF/HF ratio values from baseline to testing in both gilts and barrows are neurophysiological evidence of comparable mechanisms underlying behavioural responses when exposed to a novel situation. However, since gilts had a significantly higher $\mathrm{LF} / \mathrm{HF}$ ratio than the barrows, it is possible to argue that the mechanism was regulated on a different level. The fact that we found no changes in RMSSD and HF, in parameters that were previously used as indicators of vagal activity in cattle (Després et al., 2002; Kovács et al., 2014) and pigs (Zebunke et al., 2011), leads us to assume that our results point to a general increase in sympathetic activation. The increased LF/HF ratio by variations in sympathetic input was interpreted earlier in relation to a stressful context in sheep (Coulon et al., 2011). If we consider the changes in the sympathetic system to represent the arousal dimension of effect with negative valence (Yeates and Main, 2008), then the degree of aversiveness of the stimuli in the NAT was greater in barrows than in gilts as indicated by the greater increase in LF/HF. Owing to this and other reports (Porges, 1995; Friedman and Taylor, 1998), it is reasonable to think that barrows showed higher stress susceptibility during exposure to stressors in the NAT for having a higher $\mathrm{LF} / \mathrm{HF}$ compared to gilts.

Our behavioural results indicate that environmental stimuli in the NOT (but not in the NAT) induced different behavioural responses in gilts when compared with barrows, which goes in line with a review by Forkman et al. (2007), who documented that specific responses of an individual depend on the nature of the novelty-related stimulus due to fluctuations in environmental or motivational variables. Furthermore, our results may also indicate different concepts of optimal exploratory strategy in gilts compared with barrows. As found for the behavioural responses, cardiac responses were not consistent over the two fear tests. While autonomic regulation of the heart varied in pigs of different sexes in the NAT, no such difference was found in the NOT. According to our results, we cannot fully confirm the previous findings showing that stress affects the sexes differently (Kritas and Morrison, 2007), but it is suggested that the response depends on the type of stressor presented.

Analyzing breed, LYLD pigs in comparison with LY pigs had a longer attention towards the novel object and a lower level of avoidance or fearfulness as indicated by showing longer duration of contact with a novel object in the NOT. Showing more lying, standing, and walking as indicators of less goal attention, a lower excitement for a novel object is furthermore confirmed in LY pigs. In the NAT, the exposure to novel stimuli elicited alterations in behavioural responses in LY pigs showing shorter latency to excrete, more standing, and less walking compared with LYLD pigs. Following the argument that a decreased motor activity level is an indicator of a perception of decreased control over the environment, which is stress-induced, while an increased level reflects an attempt of the animal to extricate itself from its surroundings prior to the onset of the learned helplessness (Hughes and Duncan, 1988), LY pigs seem to be more stressed in the NAT while less in the NOT when compared with LYLD pigs. From the measurements of baseline cardiac activity, we would expect LY pigs to be less stressed or more adaptive in the challenging situations, 
but this was evident only during exposure to a novel object that they could manipulate in a familiar environment.

We reported a significant increase in HR from baseline to testing in LYLD pigs, which was greater than what we observed for LY pigs during the exposure to stressors in the NAT. We thus found an impact of the breed on the magnitude of change that may represent the net interaction between vagal and sympathetic regulation (Camm et al., 1996). Increased HR is usually accompanied by vagal withdrawal (Sato et al., 2004) and this was numerically confirmed in our study by the lower RMSSD and HF from baseline to testing. Similar HR dynamics by fear-related response of HR and sympathetic activation has been described before (Stiedl et al., 2009). An alteration in HR but not in LF/HF ratio was reported by Visser et al. (2002) when investigating a reaction to psychological stress in horses. Based on our results and if we consider the changes of the sympathetic system to represent the arousal dimension of effect proposed by Yeates and Main (2008), we propose that LYLD pigs were more aroused by the stimuli in a socially isolated novel environment when compared with LY pigs.

In the NOT, both sex and breed had a significant impact on pig behaviour, with an exception of the latency to approach a novel object, while in the NAT it was only breed. A display of similar latency can be explained by the fact that pigs are in general curious animals that like to approach and explore new objects in their familiar environment. Interestingly, in the NOT, the results reflected neither sex nor breed influence on physiological responses in pigs, but they did in the NAT. It seems that in a novel situation that provokes an attentive response associated with excitement or fear, pigs have a similar attentive state regardless of their genetic background. This leads us to think that the exposure to a novel object may not be stressful for pigs in our study or that stimuli in the NAT were more stressful compared with the stimuli in the NOT, which supports our hypothesis. Another explanation for the obtained results is a small sample size used that may have prevented detection of existing genetic influence on autonomic regulation in the NOT.

A strong positive correlation was found between LF on the one hand and RMSSD and HF on the other hand during baseline conditions in gilts and the two investigated breeds. The same correlations were witnessed during test period in the NOT. In the NAT, the positive correlation was found in both sexes and in LYLD pigs. Finding these correlations emphasizes the strong association of LF with vagal activity in pigs from pens with tail biting outbreaks. The same relationship has been reported in humans with anxiety disorder such as panic (Friedman and Thayer, 1998).
The cardiac activity of different sexes and breeds did not respond to all stress in the same way because the response was dependent on the type of stressors presented. It is justified to assume that responses to stressors in a novel environment found in the current study led to an expression of emotion, possibly, fear, which was accompanied by elevated sympathetic tone. Although previous experience (i.e., phenotypic effects) could be problematic for the validity of baseline and reactive measures and present a confounding influence that cannot be excluded from the considerations here, our results give evidence that the sympathetic tone is more involved as a mediator of stress to the heart than vagal tone.

\section{Conclusions}

Pigs display complex behavioural and physiological interactions that characterize responses to social isolation in familiar and novel environments with differences relating to genetic background. Barrows seem to be less explorative than gilts and to have a higher level of fearfulness. When barrows are socially isolated in a novel environment, they have a higher low/high frequency band power ratio. Landrace/Yorkshire $\times$ Landrace/Duroc pigs are animals that perform more manipulative behaviours when occupied with a novel object, which may indicate a lower level of fearfulness than Landrace $\times$ Yorkshire pigs. By showing higher heart rate responses, Landrace/Yorkshire $\times$ Landrace/Duroc pigs also seem to get more aroused by novel stimuli in a socially isolated novel environment. Taken together, heart rate variability data can be an informative physiological measure related to presumed psychological processes in different sexes and breeds of pigs previously housed in pens in which tail biting occurs.

\section{Acknowledgments}

This work was funded by the Nordic Joint Committee for Agricultural Research and the Norwegian Research Council, project number 188520, awarded to Adroaldo José Zanella. We would like to thank CAPES for the support granted to Adroaldo José Zanella. We would also like to thank Carlos Ventura, Hanna Lind Johansen, Kristian Ellingsen, Laura Travers, and Karine Hesle for their assistance and practical help with data collection. Jan Langbein is acknowledged for providing essential knowledge of Polar software. Special thanks go to the Norwegian farmers for participating in the project. The European Economic Area grant provided to Manja Zupan a financial help for engagement in the project. We would like 
to thank Andrew Janczak, who was involved in the planning of the experiment, data collection, and discussions about the study.

\section{References}

Camm, A. J.; Malik, M.; Bigger, J. T.; Breithardt, G.; Cerutti, S.; Cohen, R. J.; Coumel, P.; Fallen, E. L.; Kennedy, H. L.; Kleiger, R. E.; Lombardi F.; Malliani A.; Moss, A. J.; Rottman, J. N.; Schmidt, G.; Schwartz, P. J. and Singer, D. H. 1996. Heart rate variability: standards of measurement, physiological interpretation, and clinical use. European Heart Journal 17:354-381.

Coulon, M.; Hild, S.; Schroeer, A.; Janczak, A. M. and Zanella, A. J. 2011. Gentle vs. aversive handling of pregnant ewes: II. Physiology and behavior of the lambs. Physiology \& Behavior 103:575-584.

Després, G.; Veissier, I. and Boissy, A. 2002. Effect of autonomic blockers on heart period variability in calves: evaluation of the sympatho-vagal balance. Physiological Research 51:347-353.

Forkman, B.; Boissy, A.; Meunier-Salaün, M. C.; Canali, E. and Jones, R. B. 2007. A critical review of fear tests used on cattle, pigs, sheep, poultry and horses. Physiology \& Behavior 92:340-374.

Friedman, B. H. and Thayer, J. F. 1998. Anxiety and autonomic flexibility: a cardiovascular approach. Biological Psychology 47:243-263.

Geverink, N. A.; Schouten, W. G. O.; Gort, G. and Wiegant, V. M. 2002. Individual differences in behavioral and physiological responses to restraint stress in pigs. Physiology \& Behavior 77:451-457.

Hansson, I.; Hamilton, C.; Ekman, T. and Forslund, K. 2000. Carcass quality in certified organic production compared with conventional livestock production. Journal of Veterinary Medicine Series B Infectious Diseases and Veterinary Public Health 47:111-120.

Hughes, B. O. and Duncan, I. J. H. 1988. The notion of ethological 'need', models of motivation and animal welfare. Animal Behavior 36:1696-1707.

Jensen, P.; Rushen, J. and Forkman, B. 1995. Behavioural strategies or just individual variation in behaviour? - A lack of evidence for active and passive piglets. Applied Animal Behavior Science 43:135-139.

Korte, S. M.; Olivier, B. and Koolhaas, J. M. 2007. A new animal welfare concept based on allostasis. Physiology \& Behavior 92:422-428.

Kovács, L.; Jurkovich, V.; Bakony, M.; Póti, P.; Szenci, O. and Tőzsér, J. 2014. Welfare assessment in dairy cattle by heart rate and heart rate variability - Literature review and implications for future research. Animal 8:316-330.

Kritas, S. K. and Morrison, R. S. 2007. Relationships between tail biting in pigs and disease lesions and condemnations at slaughter. Veterinary Record 160:149-152.

Marchant-Forde, R. M.; Marlin, D. J. and Marchant-Forde, J. N. 2004 Validation of a cardiac monitor for measuring heart rate variability in adult female pigs: accuracy, artefacts and editing. Physiology \& Behavior 80:449-58.

Mohr, E.; Langbein, J. and Nürnberg, G. 2002. Heart rate variability: a noninvasive approach to measure stress in calves and cows. Physiology \& Behavior 75:251-259.

Porges, S. W. 1995. Cardiac vagal tone: a physiological index of stress. Neuroscience \& Biobehavioral Reviews 19:225-234.

Sato, K.; Matsuo, H.; Katayama, K.; Ishida, K.; Honda, Y.; Katsumata, K. and Miyamura, M. 2004. Ventilatory and circulatory responses at the onset of voluntary exercise and passive movement in sprinters. European Journal of Applied Physiology 92:196-203.

Stiedl, O.; Jansen, R.F.; Pieneman, A.W.; Ögren, S.O. and Meyer, M. 2009. Assessing aversive emotional states through the heart in mice: implications for cardiovascular dysregulation in affective disorders. Neuroscience \& Biobehavioral Reviews 33:181-190.

Taylor, N. R.; Main, D. C. J.; Mendl, M. and Edwards, S. A. 2010. Tail-biting: A new perspective. Veterinary Journal 186:137-147.

Visser, E. K.; van Reenen, C. G.; van der Werf, J. T. N.; Schilder, M. B. H.; Knaap, J. H.; Barneveld, A. and Blokhuis, H. J. 2002. Heart rate and heart rate variability during a novel object test and a handling test in young horses. Physiology \& Behavior 76:289-296.

von Borell, E.; Langbein, J.; Després, G.; Hansen, S.; Leterrier, C.; Marchant-Forde, J.; Marchant-Forde, R.; Minero, M.; Mohr, E.; Prunier, A.; Valance, D. and Veissier, I. 2007. Heart rate variability as a measure of autonomic regulation of cardiac activity for assessing stress and welfare in farm animals - a review. Physiology \& Behavior 92:293-316.

Walker, P. K. and Bilkei, G. 2006. Tail-biting in outdoor pig production. The Veterinary Journal 171:367-369.

Zebunke, M.; Langbein, J.; Manteuffel, G. and Puppe, B. 2011. Autonomic reactions indicating positive affect during acoustic reward learning in domestic pigs. Animal Behavior 81:481-489.

Zupan, M.; Janczak, A. M.; Framstad, T. and Zanella, A. J. 2012. The effect of biting tails and having tails bitten in pigs. Physiology \& Behavior 106:638-644.

Yeates, J. W. and Main, D. C. J. 2008. Assessment of positive welfare: a review. Veterinary Journal 175:293-300. 